\title{
The Effect of Premolar Extraction on Bolton Overall Ratio in Class I Malocclusion at RSGMP FKG USU
}

\author{
Mutia Amalia Nasution \\ Specialist Program of Orthodontic \\ Department of Orthodontic \\ Faculty of Dentistry University of North Sumatera \\ Medan, Indonesia \\ mutiaamalianst@gmail.com
}

\author{
Siti Bahirrah, Amalia Oeripto \\ Department of Orthodontic \\ Faculty of Dentistry University of North Sumatera \\ Medan, Indonesia
}

\begin{abstract}
In orthodontics treatment, to obtain a good and stable occlusion, harmony between the combined mesiodistal width of maxillary teeth and that of mandibular teeth must be attempted. Extraction of premolar is routinely carried out as part of orthodontic treatment, but it can lead to the changes of the overall Bolton ratio and the changes are influenced by different extraction combinations. The purpose of this study is to investigate the effects of premolar extraction on the overall Bolton ratio in Class I malocclusion patients. Mesiodistal tooth width of $\mathbf{4 0}$ pretreatment dental casts of subjects with Class I malocclusions was measured with $0.01 \mathrm{~mm}$ accuracy digital caliper. The overall ratios and tooth-size discrepancies were determined before and after hypothetical premolar extractions. Before and after extractions, the subjects were divided into small, normal, and large overall ratio groups categorized by the Bolton \pm standard deviation definition. Extractions were performed in the following combinations: (1) all first premolars, (2) all second premolars, (3) maxillary first and mandibular second premolars, and (4) maxillary second and mandibular first premolars. Statistical evaluations were performed using One-way ANOVA analysis, Wilcoxon Signed Rank test. Results showed that the overall ratios decreased after extraction in any combinations of premolars. The subjects in Bolton small group were still in small group after extractions. Some subjects of the Bolton normal group were then categorized as Bolton normal and Bolton small after extractions. Most subjects of the Bolton large were classified as the Bolton normal group after extractions. It is concluded that the four premolar extraction combinations had significant impact on the overall Bolton ratio; the overall Bolton ratio is decreased after extraction of premolar in any combinations of extraction.
\end{abstract}

Keywords-overall Bolton ratio, class I malocclusion, hypothetical extraction

\section{INTRODUCTION}

The need for orthodontic treatment is increasing each year. The objective of orthodontic treatment is to obtain optimal overjet and overbite, good aesthetics, good final occlusion, and good stability. One of the factors which plays an important role in achieving the goal is the harmony in the width of maxillary and mandibular mesiodistal teeth $[1,2,3]$.

Class I skeletal malocclusion is a common malocclusion. Aldress (2012) conducted his study on 602 orthodontic patients in Saudi Arabia. The result showed that Class I skeletal malocclusion was the most commonly found. Wijayanti, et al (2014) showed that of 98 subjects, $65.3 \%$ had Class I malocclusion[6,7,8].

The tooth size is the most important parameter in establishing a diagnosis and developing orthodontic treatment plan. The inappropriateness of dental size (discrepancy) is the primary cause of malocclusion. Bolton analysis is one of the easiest and most helpful analysis in determining discrepancy of the tooth size between maxilla and mandibles to develop treatment plan $[1,7,8]$.

Some studies show that overall Bolton ratio will change after dental extraction. Bolton (1962) and Yang (2002) pointed out that overall Bolton ratio will decrease after the extraction of the first four premolars. Meanwhile, the study by Varghese ST, et al. (2016) conclude that overall Bolton ratio will increase after the extraction of the first premolars and will decrease after the extraction of the second premolars $[3,9,10,11,12]$.

Saatchi proposed that changes of overall Bolton ratio were only significant in four extraction of first premolar and were not significant in the other extraction combinations. The overall Bolton ratio will increase after extraction of all first premolars, extraction of maxillary first premolars and mandibular second premolars, but will decrease after extraction of all second premolars and extraction of maxillary second premolars and mandibular first premolars. Varghese ST et all (2016) concluded that overall Bolton ratio will increase after extraction of first premolars and will decrease after extraction of second premolars $[3,11,12,13]$.

The influence of the extraction of premolars on overall Bolton ratio is essential in obtaining comprehensive understanding as guidance for treatment planning. 


\section{MATERIALS AND METHODS}

This is a quasi experimental study with cross sectional design. The samples consisted of 40 study models of RSGM FKG USU patients with Class I malocclusion. The category of Class I malocclusion was ANB $\pm 2-4^{\circ}$ for male and female patients. The first permanent molars of subjects were Class I in both sides. The range of the sample age was 17 to 35 years old. Management of the study was in accordance with the study method conducted by Endo Toshiya, et al. [12].

Digital caliper (Mitotoyo) with accuracy of $0.01 \mathrm{~mm}$ was used to measure the mesiodistal width of teeth, from the first molar to the first molar. The mesiodistal width of each tooth was measured in the widest range among contact points on proximal surface. Overall Bolton ratio was determined according to Bolton method. It was then categorized on the normal, small, or big Bolton ratio.

The premolars were then extracted hypothetically by changing the width of extracted mesiodistal premolars with zero number (0). The combinations of the extraction were divided into 4 (four) groups: (1) extraction of the first four molars, (2) the second premolars, (3) the first maxillary premolars and the second mandibular premolars, and (4) the extraction of the second maxillary premolars and the first mandibular premolars.

One-Way ANOVA test was used to determine influence of extraction combinations on overall Bolton ratio. Post Hoc test was used to find out the disparity. Non-parametric data or ordinal data were gathered by using Wilcoxon Signed Rank test and Chi Square test.

\section{RESULTS}

Overall Bolton ratio decreased after the extraction of premolars. The decrease occurred in all combinations of extraction. The result of One-Way ANOVA test on the value of overall Bolton ratio after the extraction could be seen in Table I.

TABLE I. DISTRIBUTION OF OVERALL BOLTON RATIO AFTER THE EXTRACTION OF PREMOLARS

\begin{tabular}{|l|c|c|c|}
\hline \multicolumn{1}{|c|}{ Overall Bolton ratio } & $\mathbf{n}$ & $\mathbf{X} \pm$ SD (\%) & P \\
\hline Before & 40 & $91.40 \pm 1.78$ & ----- \\
Exo 4 P1 & 40 & $89.99 \pm 1.77$ & $0.02^{*}$ \\
Exo 4 P2 & 40 & $89.01 \pm 1.64$ & $0.00^{*}$ \\
Exo P1 RA \& P2 RB & 40 & $89.01 \pm 1.64$ & $0.00^{*}$ \\
Exo P2 RA \& P1 RB & 40 & $88.96 \pm 1.51$ & $0.00^{*}$ \\
\hline
\end{tabular}

The result of One-Way ANOVA test, followed by Post Hoc test on the influence of the extraction of premolars could be seen in Table II.

TABLE II. DISTRIBUTION OF THE INFLUENCE OF THE EXTRACTION OF PREMOLARS ON OVERALL BOLTON RATIO

\begin{tabular}{|l|c|c|c|c|c|}
\hline $\begin{array}{c}\text { Overall } \\
\text { Bolton } \\
\text { Ratio }\end{array}$ & $\begin{array}{c}\text { Before } \\
\text { Extraction }\end{array}$ & $\begin{array}{c}\text { Extraction } \\
\mathbf{4 ~ P 1}\end{array}$ & $\begin{array}{c}\text { Extraction 4 } \\
\text { P2 }\end{array}$ & $\begin{array}{c}\text { Extraction } \\
\text { Maxilla P1 } \\
\mathbf{\&} \\
\text { Mandibular } \\
\text { P2 }\end{array}$ & $\begin{array}{c}\text { Extraction } \\
\text { Maxilla P2 } \\
\text { \& } \\
\text { mandibular } \\
\text { P1 }\end{array}$ \\
\hline Small & 4 & 14 & 21 & 17 & 24 \\
Normal & 29 & 25 & 19 & 23 & 16 \\
Big & 7 & 1 & 0 & 0 & 0 \\
Total & 40 & 40 & 40 & 40 & 40 \\
\hline
\end{tabular}

\section{DISCUSSION}

The result of the study showed that the extraction of premolars could cause the value of overall Bolton ratio to decrease significantly. The decrease occurred in all hypothetical extractions. This was in accordance with the research conducted by Bolton (1962), Tong H, et al (2004), and Yang (2002). However, it was incompatible to the research conducted by Endo, et al (2010). This was due to disparity in the normal Bolton value used as reference. In his research, Endo, et al used the mean value of normal Bolton at $88 \%$, while the research conducted by Tong, et al used the mean value of Bolton at $91.3 \%$ (similar to this study) $[12,15]$.

Different extraction combination showed difference in the result. In this study, the combination of the extraction of the second four premolars and the combination of the extraction of the second maxillary premolars and the first mandibular premolars mostly changed to small Bolton or mostly decreased. This allegedly occurred because the width of mesiodistal of the second maxillary premolars was smaller than the width of the first mandibular premolars so that overall Bolton ratio would shrink during the extraction of the second maxillary premolars, compared to the extraction of the first maxillary premolars $[3,10,11,15]$.

\section{REFERENCES}

[1] K.P. Vilas, C.D. Rajendra, K.S. Shailendra, "Extraction: A parameter in Bolton ratio," Journal of Dental and Allied Sciences, vol. 4(1), pp. 3-7, 2015.

[2] P. Kanniyapan, B. Saravanaan, Thulasiram, "Changes in traditional Bolton's ratio with various extraction combinationAn in vitro study," Biomedical \& Pharmacology Journal, vol. 8(Sp; Ed.), pp. 647-653, 2015.

[3] S.T. Verghese, P.R. Yerasi, "Outcome of premolar extraction on Bolton's overall ratio and tooth size discrepancy in South India,” J. Int. Soc. Prev. Community Dent., vol. 6(4), pp. 309315, 2016.

[4] M.A. Abdullah, "Pattern of skeletal and dental malocclusions in Saudi orthodontic patient," Saudi Med. J., vol. 33(3), pp. 315320, 2012.

[5] P. Wijayanti, Krisnawati, N. Ismah, "Gambaran maloklusi dan kebutuhan perawatan ortodonti pada anak usia 9-11 tahun (studi pendahuluan di SD At-Taufiq, Cempaka Putih, Jakarta),” Jurnal PDGI, vol. 63(1), pp. 25-29, 2014.

[6] M.M. Rahman, "Pattern of malocclusion in patient seeking orthodontic treatment at Dhaka Dental Collage and Hospital," Ban. J. Orthod. and Dentofac. Orthop., vol. 3(2), pp. 9-11, 2013.

[7] R.H. Cancado, "Association between Bolton discrepancy and angle malocclusions,” Braz. Oral Res., vol. 29(1), pp. 1-6, 2015.

[8] D.S. Fulari, "Seven key of occlusion," International Journal of Contemporary Medical Research, vol. 3(7), pp. 2108-2110, 2016.

[9] W.A. Bolton, "Disharmony in tooth size and its relation to the analysis and treatment of malocclusion," Angel Orthod., pp. 113-120, 1958.

[10] S.A. Othman, H. Mookin, "Bolton tooth size discrepancy among University of Malaya dental student," Annal Dent. Univ. Malaya, vol. 15(1), pp. 40-47, 2008.

[11] T. Haoyu, C. Danpeng, X. Lei, L. Ping, "The effect of premolar extraction on tooth size discrepancies," Angle Orthodontist, vol. 74(4), pp. 508-511, 2004.

[12] E. Toshiya, I. Katuyuki, S. Isao, "Effect of premolar extractions on Bolton overall ratio and tooth-size discrepancies in a Japanese orthodontic population," Am. J. Orthod. Dentofacial Orthop., vol. 137(4), pp. 508-514, 2010.

[13] W. Barbara-Szulc, J. Joanna, P. Stepien, "Overall and anterior Bolton ratio in class I, II, and III orthodontic patients," European Journal of Orthodontics, vol. 32, pp. 313-318, 2010. 
[14] S. Sastroasmoro, S. Ismail, Dasar-dasar metodologi penelitian klinis, edisi 4. Jakarta: Sagung Seto, 2011, pp.130-145.
[15] K. Pius et al., "Effect of premolar extraction on Bolton overall ratio and tooth-size discrepancies in a North Indian Population,' J. Orthod. Sci., vol. 2(1), pp. 23-27, 2013 